\title{
Methods of formulating business goals implemented in ERP accounting systems
}

\author{
Radka Vaníčková1 \\ ${ }^{1}$ Institute of Technology and Business in České Budějovice, Department of Management, \\ Czech Republic
}

\begin{abstract}
The importance of technological innovations is gaining in intensity with the growth of production, distribution and expansion abroad, together with the development of the potential of knowledge workers. The use of automation in robotic processes is used in business processes, which allows increasing productivity in individual parts of processes. The ERP system can accelerate and support efficiency in the supplier and customer process, e.g. in conjunction with Customer Relationship Management. The aim of the paper was to implement an ERP accounting system for a specific project of a company in an international corporation. The aim of the project was to increase the efficiency of accounting operations, simplify the process of recording invoices in the system, and increase the security of the system so that it meets the requirements of accounting audit and IFRS. The primary method used was the logical framework method, which dealt not only with setting business objectives, but also with project management in general, taking into account project management and measurable project outputs, albeit with low / minimum added value and gross time risk.
\end{abstract}

Keywords: business goals, methods SMART \& CLEAR, Objective Key Results, Logical Frame Logframe, ERP accounting system

\section{Introduction}

In project management, there is a dynamic development thanks to new information technologies, the development of software designed for project managers and rapidly changing trends responding to the basic and specific needs of non-traditional companies. Partial work activities and orders can be recorded in projects implemented in project management with the ability to monitor budgets, including the use of resources, assign tasks, check deadlines, report (Ploder, Dilger and Bernsteiner, 2020). The ERP system 
automates and integrates key business processes, such as receiving customer orders (Reisenwitz and Fowler, 2019), planning operations, keeping inventory records (Wei et al., 2020) and financial data (Astanakulov, 2019). It offers parametrization of functions, as well as space for the development and integration of specific customer/company/employee requirements, as well as the introduction of new approaches in production with regard to innovations in Industry 4.0. ERP systems help improve organizational efficiency by helping to define business processes throughout the supply chain (Bing, Yang and Kang, 2020), protect business data through specified roles and provide access (Nývlt, 2018) allow to plan work time based on existing orders and forecasts, and provide tools implemented in basic and specific customer services, transform data for managerial decision making purposes (Erskine, Khojah and McDaniel, 2019).

The formulation of objectives plays an irreplaceable role in project management during the entire project life cycle, but also in terms of a future contract with a supplier or service provider in cooperation with the development of outsourcing and the role of external teams cooperating on remote projects. The goals of a corporate project influence the planning processes of the project (Huikku, Hyvönen and Järvinen, 2017); define its timing, financial framework (Andreeva et al., 2019) selection of methods and procedures used for project implementation. Furthermore, they play an irreplaceable role in control processes (Wu et al., 2019) as they provide a framework for measuring indicators, including the informative value of the results achieved (Głodziński, 2019). The exact formulation of business goals is partial for communication between the project manager, the sponsor and the project team (Pearson, 2019). If third parties are also involved in the project, a contract with a detailed description of business objectives, time frame for achievement and the budget defined above is a necessary parameter, which also serves as legal support across the life stages of the project. The contract, which confirms the binding nature of the wording of corporate goals, determines the conditions for a good level of project communication during the life of the project and is the bearer of the formulation of final, evaluation and monitoring reports.

In the first part of the paper, the author points to the methodology of formulating business objectives implemented in the ERS accounting system (Enterprise Resource Planning) from a theoretical point of view (Izhar et al., 2018) and with the help of literature sources interprets methods of formulating business objectives, including evaluation of benefits/expectations, advantages/disadvantages, risks/limitations (Bočková, Gabrhelová and Vaníčková, 2017). She takes into account technological possibilities in the formulation of business goals through the application of computer modules as support tools for project managers applied to accounting systems (My Le, Hoang Tran and Thuy Tran, 2018) and (Sankaran and O'Brien, 2018).

The analytical part is devoted to a case study of the project of implementation of a new accounting system (Pan, Teoh and Seow, 2014), including a comparison of theoretical and application presumptions of the researched topic of business objectives formulation with an emphasis on critical and analytical thinking, strategic approach to defining goals 
(Kitsios et al., 2019) and systematic decision-making (Colapinto, Jayaraman and La Torre, 2020), which was not entered into a contract with the service provider at the beginning of the project, there was no inaccurate description of business goals and methods used to formulate business goals, which had a major impact on the project life cycle (MartínezBlanco, Forin and Finkbeiner, 2020), as it could cause project failure. The author of the paper asked herself the question: "How would the possible use of a higher number of research methods adversely affect the course and time of implementation of a project that was classified as successful, even though it lasted twice as long as planned and led to the departure of several key employees?"

One of the basic methods to help formulate business goals was the SMART method, which defines the basic parameters of business goals.

\section{SMART method for formulating business goals}

S: Specific - Goals should be specific and concrete. Specification of the goals can be determined using the 5 W method, i.e.: "WHO, WHAT, WHERE, WHEN, WHICH and WHY". M: Measurable - goals must be measurable. Based on measurable parameters, it is possible to determine whether the goal has been achieved. The value must be repeatedly measurable using the same methodology. The KPI (Key Performance Indicators) method measures the time, quality and budget of a project that is part of the company's goals.

A: Assignable - goals can be assigned to someone and the responsibility for achieving them can be defined.

R: Realistic - goals should be feasible and achievable with the help of available resources.

T: Time-bound - goals should be time-bounded.

The benefit of the SMART method is the design of specific objectives of the organization with the definition of procedures how to achieve the objectives. The advantage is the decision on the choice of alternatives for future ways of performing activities and the possibility of project management within the strategic management. The disadvantage is to a large extent subjectivity and error in the formulation of goals in relation to the external and internal environment (Bershadsky et al., 2019). The KPI method is beneficial from the point of view of setting indicators and performance indicators in the process, service, department and the whole company in relation to quality, efficiency (Akhanova et al., 2018) and economy. The advantage of the method is measurable value, which interprets the achievement of the level of effectiveness of key business goals within the evaluation of processes in individual departments, such as sales, marketing (Feng et al., 2020) and human resources. The disadvantage and risk is the formulation of inappropriate indicators that do not have a positive effect on a positive change in the organization, may limit the sharing of information between business processes (Mousaei and Gandomani, 2018). 


\section{Objective Key Results (OKR) method}

The OKR objective setting system is based on the MBO (Management by Objectives) method and their interpretation was advocated by John Doerrem from Google. The OKR method is similar to the KPI method, as both methods are used to measure the company's performance and goals; however, they differ in their intended use. The KPI is applied to show the performance of teams with respect to the set business goals, as it takes more account of the quantitative side and reflects the current state of fulfilment of business goals in relation to individual team members. OKR displays the general comprehensive goals of the organization, including priorities at the strategic level, while KPI is integrated into the individual performance of the employee / teams for regular inspections and feedback in order to achieve key results according to project success / failure.

The following rules apply to the OKR method:

The main objectives should be a maximum of 3-5, each of which should have about 5 measurable and clearly defined Key Results. Specifically, defined Initiatives should lead to the fulfilment of Key Results. OKR should be divided according to the following pyramid within the whole organization/individual departments/individuals. The ideal state can be achieved on the assumption that each employee fulfils 3-5 formulated objectives, then the success of fulfilling the objectives moves along the vertical axis upwards to meet the complete/global goal of the organization/company. The OKR method is an ideal project management tool because it simply shows which activities are to be performed in summary. The benefit of the OKR method is the systematic assessment of the company's mission and vision of all employees who contribute to the company's goals. The disadvantage is the formulation of smaller objectives, for which only individual departments are responsible, not individuals, which is a limitation mainly for larger companies with more than 25 employees.

\section{CLEAR method for formulating business goals}

A newer method of goal setting, which takes into account the rapidly changing turbulent environment of international companies reflecting challenges and taking into account the human factor in the business environment, is a method for formulating business goals called CLEAR.

C: Collaborative - Objectives should encourage employees to work together and support team spirit.

L: Limited - Objectives should be limited in scope and time so that it is clear that the limit values are realistic.

E: Emotional - Objectives should motivate employees; evoke a certain enthusiasm and emotions that have a positive effect on the quality of work performed.

A: Appreciable - The generally defined objective should be divided into smaller subobjectives, for the achievement of which the employee should be provided with adequate remuneration. 
R: Refinable - Objectives should be easily achievable to respond flexibly to unexpected changes and accidental, often unpredictable situations, according to the needs of the dynamics of a changing environment and working conditions.

\section{Logical framework method}

Logical Frame Logframe or LFA is a methodology of project management, which not only solves the setting and formulation of goals, but uses all project stages within the entire project, i.e. the planning, implementation and evaluation phases of the project (American University Washington, 2020). The method defines a logical framework of conditions for meeting the objectives of a complex project. The matrix of the logical frame contains a table with about 16 components (15 to 17 fields), which are interpreted in columns or rows in terms of the vertical axis of the logic of the frame with respect to the horizontal logic of the frame - see figure 1.

The advantage of the logical framework method is the formulation of key project parameters before starting the project in the pre-project phase. The form of output is a logical frame called a document. The outputs of the project are not added value or justification for the actual implementation of the project. The risk is a rough estimate of the time required, which can be defined as the interval with the implementation of partial activities.

Figure 1: Logical Frame Logframe

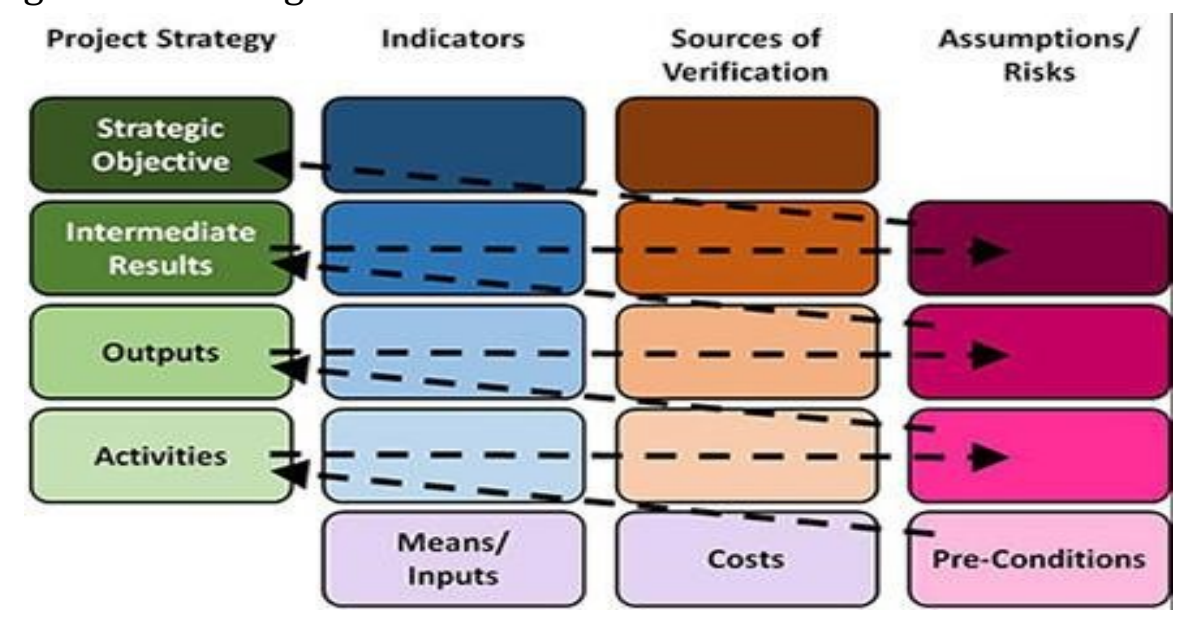

Source: American University Washington, 2020.

It is important to take a closer look at Czech-English terminology, as the terms goal and objective are often confused:

The Goal/Overall objective/Development objective, e.g. general, global, overall goal/intention, benefit of the project.

The Purpose/Immediate objective, i.e. the purpose/partial, immediate objective of the project.

The Outputs; The Activities of the project. 
The general goal of the project is to define the main goal of the project, which determines the direction of the project and the final result of the complex project. The global goal refers to the strategic need of the company and the main purpose of business development, which is to be fulfilled by the implementation of the project. The overall goal is often elaborated in more detail into a hierarchical structure of immediate objectives, which are the bearers of the requirements of the contracting authority and the future project implementer. A project logical framework is a type of matrix that interprets logical relationships in a project. In terms of the vertical dimension, it reflects the relationships between global goals and specific objectives, project outputs and sub-activities. It points out the assumptions and risks of the project, but also the causes and consequences. The horizontal line consists of 4 columns with verifiable indicators, key indicators and data sources. In terms of logical links, each column on the horizontal line has information from the previous column, which dissimilates, while on the vertical axis when reading the table upwards, each row encourages activities to achieve a higher level of objectives and global/overall goal. Logical links, vertical or intervention logic should be an integral part of the logical framework in the cause/effect/consequence line. The relationships in the table can be verified by the so-called if-then method.

\section{Methods and Data}

The aim of the project was to increase the efficiency of accounting operations, simplify the process of registering invoices in the system, increase the security of the system to meet the requirements of accounting audit and international financial reporting standard, but also reduce operating costs. The ERP accounting system was presented in the theoretical part as a suitable system for formulating business goals. The interconnectedness of theoretical and practical knowledge in connection with the new accounting system played an important role. The premise of the new accounting system was to ensure higher efficiency and effectiveness compared to the original system in order to improve the transfer of information by testing the system itself. The output was a comparison of the original accounting system with the new ERP accounting system. The methods of formulating business goals, which were described in detail in the theoretical part, were applied to the ERP accounting system. The logical framework method enabled the identification of the main benefits, objectives, outputs and activities of the project in relation to the business goals. The OKR method was interpreted based on project criteria and parameters in the time interval of September 2019. The SMART and CLEAR methods designed to formulate business goals were formulated as a unified system, the aim of which was to define business goals related to the performance of individual employees.

In connection with the planning and management of resources, it was necessary to ask basic questions when choosing an ERP system:

Q1: Why do I need a better business management system?

Q2: What resources do I have available in the company? 
Q3: Which of these resources do I need to plan and manage?

Q4: In which localities do I carry out business activities?

Q5: What predictions do I expect in the future in the field of business?

Q6: Do I have a qualified workforce to implement the accounting system in operation?

Q7: Do I have a sufficient technological base for the operation of the accounting system or I am not currently interested in implementing information technology in the production process and do I use cloud storage?

To fulfil the defined goals, it was assumed:

H1: The total processing time of one incoming invoice by the application programme does not exceed the average period of 10 minutes.

H2: The number of staff required for routine accounting operations may be reduced by $30 \%$ if the quality of the work performed is the same.

H3: Each step implemented in the accounting system will be traceable and determine which employee performed the operation and when.

H4: The implementation of the system, the so-called Go Life, will take place no later than 1 year from the actual life of the project itself.

H5: Individual employees will not be involved in testing a new version of the accounting system for more than $20 \%$ of the daily working time.

H6: Budget will not exceed \$ 500 per month (\$1,000 with license).

H7. The implementation of the ERP system will require increased communication during training and testing of employees.

\section{Results and Discussion}

\section{Formulation of business goals implemented in the ERP accounting system}

In the analytical part of the paper, research methods interpreted in the theoretical part were applied to the new accounting system. The project was currently evaluated as completed, however, the analysis of the author pointed to new findings that affected the life cycle of the project in all stages. Based on the findings, the author of the paper asked a hypothetical question: "How would the unsuccessful expectations of the project be addressed if the corporate goals were formulated differently and in a different way depending on the theoretical knowledge of these research methods?"

Before the actual analysis, it is necessary to mention the specifics of the project, i.e. replacement of the Navision system with Dynamics D365 system, where for the purpose of analysis it is called ERP system, in which most middle and senior management staff participate in cooperation in partial processes of approving invoices and financial expenses including budgeting. The system is most often used in the finance and 
accounting departments in the scope of all-day work, but also in other departments, where it is used, for example, for archiving for audit purposes. The reason for replacing the original system was insufficient capacity and performance in the dynamic development and growth of the selected company, inability to consolidate accounting internationally in situations where the company has a parent company located on two continents, but also the fact that the old system did not meet internal and external audit requirements including higher security system, which seemed less reliable. Four teams collaborated on the complete testing and implementation process, two of which were external, the others internal, which operated at the company's headquarters (financial testing teams and corporate IT teams). The method of communication outside the company was implemented through the JIRA tickets system with the help of the Microsoft Teams application, whose task is to apply the technical solution to the accounting system. The main challenge was to ensure the interface of the new ERP accounting system with the existing extensive MXP database, which was used for the purpose of the ordering system and its processing took place in individual departments of a selected company specializing in tourism, specifically shipping. Given that the purpose of the new ERP system was to replace the current system, the formulation of business goals depended on technical parameters and KPI indicators measurable in the old system. In comparison with the previous situation, a comprehensive improvement of the current situation was expected for all output values with regard to increasing the efficiency of accounting operations, simplification of the invoice registration process, including ensuring greater security with regard to accounting audit requirements.

\section{Logical Frame Logframe}

On the example of the logical framework method - see attachment Tab. 1 shows the implementation of an ERP accounting system with the absence of the formulation of general business objectives.

The method of logical framework is suitable for complex implementation of projects, especially of large scale, because they can define the project strategy and partial project activities. The disadvantage of the logical framework method is the non-complex evaluation of the influence of socio-economic, financial or personnel factors, therefore it is recommended to combine the method with other supporting tools of project planning, including the formulation of corporate goals.

\section{Objective Key Results}

The Objective Key Results method was selected based on project parameters, e.g. international long-distance teams, project duration, 150-200 actively involved employees, application of a new ERP system, which is intended for almost all permanent staff as a suitable method to complete the logical framework and SMART method. , which offers a brief and quick overview of individual activities in the company / team / individual employees. Its advantage is the possibility of setting small objectives for individual employees, which support the team goals to fulfil the overall / general / global 
goals through a pyramid structure. Through partial, gradual steps, it is realistic to monitor individual employees and test their roles in the team. An example of setting business goals for a given project for a sub-period is shown in figure. 2 .

Figure 2: OKR Company for the period 09/2019

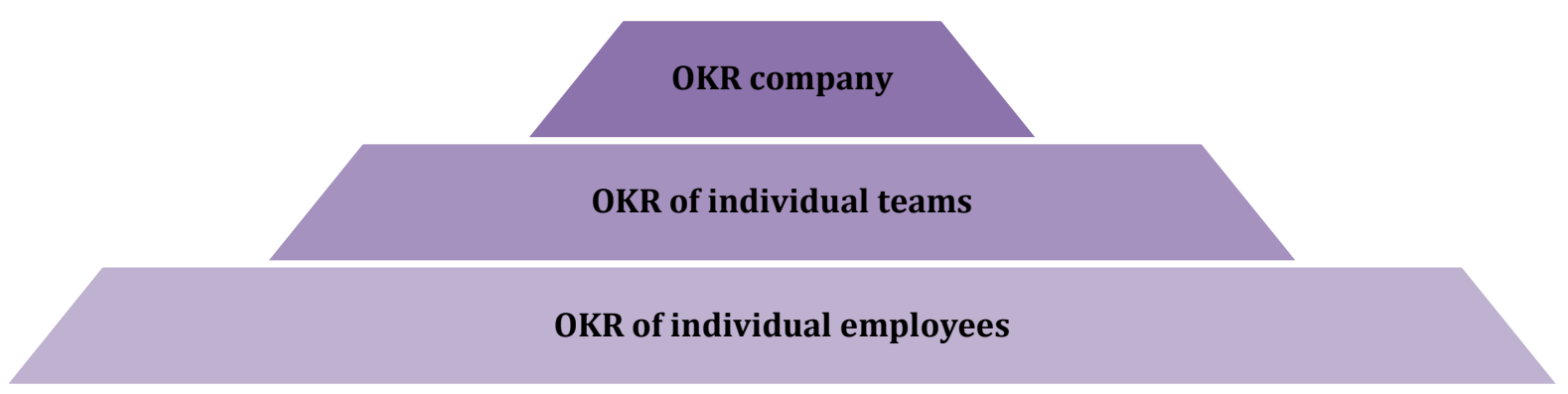

Source: Author.

To close the testing process by posting PO - purchase order invoices to the accounting system.

Objective of the financial team for the period 09/2019: Testing of all available variants of PO invoices in the accounting system.

The key results of the financial team at the end of the time period were:

Created a clear breakdown of variants of all POs and the distribution among individual employees according to testing capacities prepared at the end of the period.

Meeting with IT teams, support in individual accounting operations with argumentation of requirements in the accounting system.

Testing the system interface with the existing database on specific cases of PO on a sample of 80 invoices.

General manual for accounting of special cases.

The goals of permanent staff were set in the individual tasks assigned to them. The team manager via a shared spreadsheet file managed the ongoing performance of the financial testing team goals.

\section{SMART \& CLEAR}

The ERP system implementation project was going through a bad patch from the very start due to growing resilience of the staff involved in the testing process. The staff was not properly paid during the testing phase and did not understand the context and interfaces of the project due to closed communications. The only chance was to operate the system based on the acquisition of new knowledge and behavioural skills. The correct implementation of the ERP accounting system can be seen in figure 3. If the corporate goals and objectives were clearly formulated at the beginning of the project and integrated with the CLEAR method reflecting Appreciable, Collaborative, Emotional and Refinable there would be higher motivation, commitment and satisfaction, and teamwork 
that is more effective and the individual sub-goals would not seem distant and unattainable. The application practice of a subproject showed the project was threatened and unsuccessfully finalized although the business goals and KPIs were carefully measured in the quantitative dimension due to the underestimated motivation and commitment of permanent staff, which resulted in complete project failure with Go life postponed nearly by one calendar year.

Figure 3: Field strength diagram of the ERP accounting system implementation project
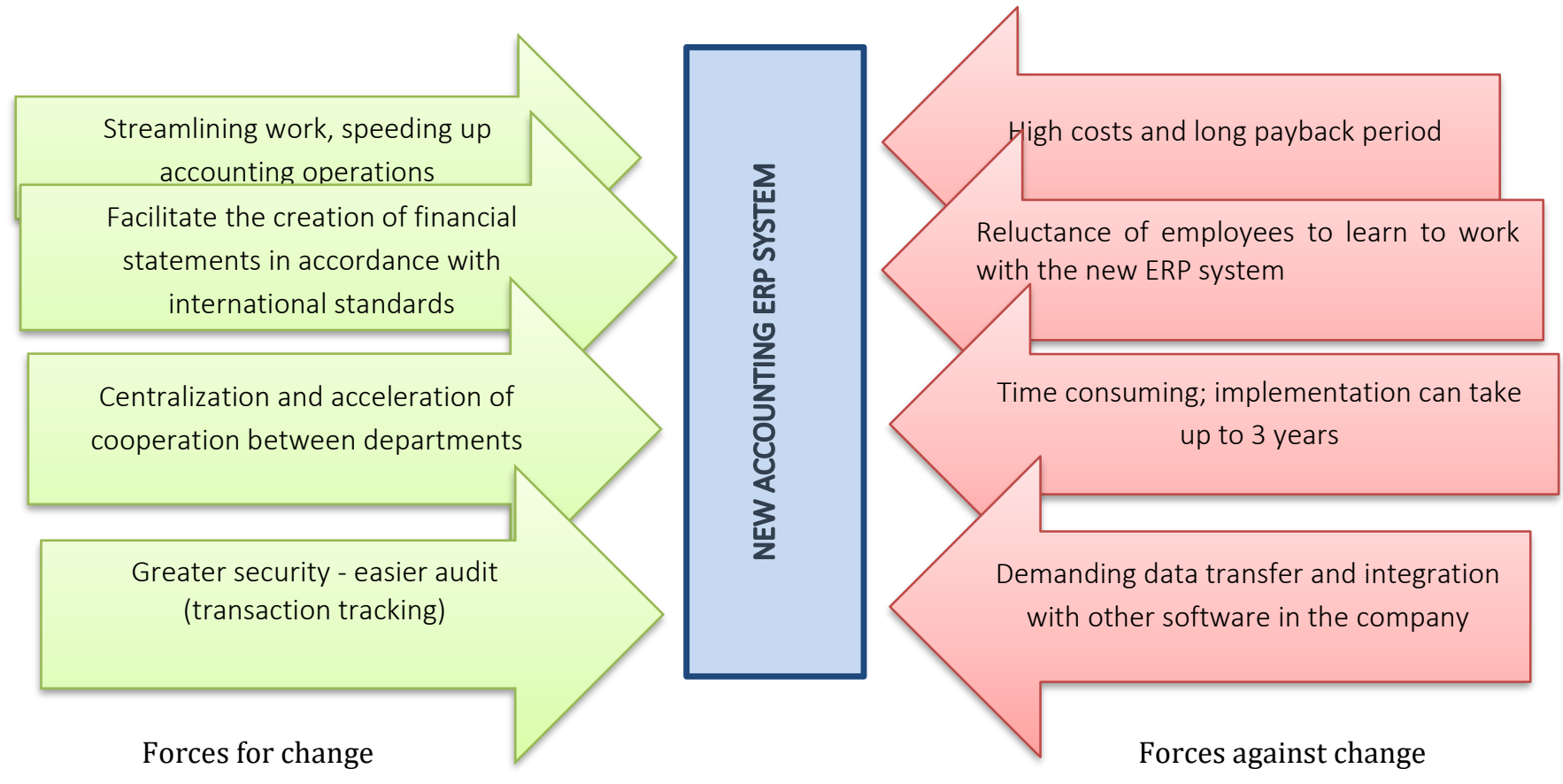

Source: Author.

\section{Conclusion}

Cloud and cloud services are nothing new as ERP and CRM software run in the cloud is the current trend. They can also be understood as the delivery of services or programs (ERP, CRM) stored on web servers. Users can access and use them remotely via a web browser. Desktop applications that require installation are slowly becoming outdated as the technological and business model of enterprise systems changes and simple registration via an Internet browser that can be purchased for any number of calendar months a year is sufficient. The operational efficiency of the system is supported by mobile applications available from Android, or Windows based operating systems, etc. It is easy to use cloud applications because you can access and retrieve information via a PC, tablet or mobile application having access to computer networks. Application solutions are affordable and regularly managed and updated by the software provider. The benefit of the ERP system implementation consisted in detailed real-time monitoring of events in the company with central data available and stored at one point with regard to data security, more efficient process management, more suitable working environment for employees, monitoring of material movement between centres, e.g. production and 
warehouse, finished products and products after warranty, etc. by exchanging data (export and import) with other systems enabling simple global integrations, e.g. exchange rates, language mutations, etc. adapted to user interface, including the access rights of individual employees. The process basis for the operation of an accounting system and the implementation of information technologies are more useful and efficient than using cloud storage. The SMART method, which allows planning, and defining business goals can be considered for implementation of an ERP accounting system. Using multiple research methods in different project phases of the project life cycle considering a number of variables challenging the actual implementation during the project life will cause discrepancies and create space for risks across all phases of the project. In view of these facts, it is desirable to innovate research methods, techniques and scientific procedures and redefine the situation with small and partial objectives to promptly respond to challenges and allow coming up with specific measures for members of the international design team operating in different foreign cultures of the Group. The drawbacks of the ERP system implementation included high investment costs, long-term ROI; financial challenges of software modifications, high license fees, and the implementation schedule which averaged 6 to 18 months, or continuous supervision.

The aim of the paper was to implement an ERP project management system for a specific company project in an international corporation. The objective of the project was to increase the efficiency of accounting operations, simplify the process for posting invoices in the system, and improve the system security to meet the requirements of IFRS and accounting audit as well as reduce the operating cost of the accounting department. In the analytical part of the paper, the Objective Key Results method was analysed by the author in more detail. It was suitable for the project as an additional method for work in individual project teams because it is more straightforward and has a simpler structure. The OKR method with a focus on a specific employee was used to confirm the total processing time of one incoming invoice by an application program not exceeding the time average of 10 minutes. The number of staff needed for routine accounting operations could be reduced by $30-35 \%$ if performance quality is maintained and each completed step can be traced to the employee who performed the operation. The deadline for the implementation of the accounting system was set for a calendar year in order to improve the quality of activities and business processes in the accounting system. The original project goals could be improved by setting small, partial project goals for individual employees to monitor the fulfilment of team goals more accurately, including the deployment of goals for individuals. The key point about choosing a method for formulating business objectives was the fact that several international teams from different continents, of which two external teams of suppliers, were involved in the project. The real life of the project was two years and approximately 200 employees were involved in it at various levels of the testing process, therefore using only the OKR method seemed insufficient. The application of the CLEAR method proved to be useful for the given object. Looking back at the life path of the implemented project to explain the reasons for the time lag, the disincentives of the individual employees involved in testing and implementation of the project should be mentioned. The lack of motivation tended to 
burnout as it was caused by the insufficient remuneration of permanent staff for their performance where testing of the new system accounted for $20-40 \%$ of daily working hours beyond routine work and activated stressors leading to emotional instability and mental fluctuations, and frustrations, or intolerance in the team, etc. As a result, the quality of teamwork, interaction and relationships in the workplace, and the corporate culture, or internal communication were affected. Long-term high commitment and working in parallel in the test environment of the new system and the real environment of the old system triggered termination of employment contracts and dismissal of several key employees. Because of this absence, the Go life process slowed down significantly. The situation would have not necessarily had such consequences if more account had been taken of the importance and impact of the CLEAR method on formulating business objectives for project teams with a view to Appreciable goals, Emotional goals, Collaborative and Refinable goals that are disregarded by quantitative methods such as OKR or Logical Frame Logframe because they strictly focus on the staff performance and KPIs without considering the hazards / risks associated with the fact that the project may fail due to lack of staff motivation and inability to work as a team, not the achievement / output of a measurable indicator. Labour intensity, complexity, and commissioning is a very time-consuming and manually challenging activity, which requires logical, strategic, and systematic thinking, and competent decision-making. The general recommendations for the implementation of an ERP and CRM system in application practice are to analyse the needs of the company, select software and modules, implement the system, provide training and testing, develop guidelines and a communication plan, motivate employees, evaluate and present the system benefits and make the system ready for everyday use. Any technical change in the ERP accounting system will require qualified workforce for the implementation and commissioning of the accounting system. The author of the paper recommends combining the ERP system with other information systems, e.g. CRM, which in many cases can run independently to meet the overall benefit expectations. Large companies most commonly use systems such as SAP, Oracle, etc. while small and mediumsized companies in the Czech Republic most often use the Czech Helios system. The SME sector has experienced a number of positive / negative changes in recent years with certain limitations / risks that should be avoided, e.g. for business stability in terms of undercapitalized business, unpredictability of external effects on business operations, failure to meet the project expectations which does not create a competitive advantage, over-optimistic visions of the company sales, unrealistic choice of business objects, and industry, or location where supply exceeds demand, and low or limited response to acceptance of a change.

The scientific literature does not provide positive references on the ERP system implementation. Just about half of the ERP implementations will fail and almost $90 \%$ of all implementation projects will not meet the schedule or exceed the planned project budget. The main reasons for failure to meet the plan included, for example, unexpected obstacles in the system functionality, which necessitated a larger scope of implementation work, or lack of technical support and the company's inability to adapt internal processes to the new ERP system. In the case of ERP, the adherence to a time schedule and financial 
plan caused deterioration in the quality and complexity of the system in relation to business processes and sub-processes and adverse consequences in the end. For successful implementation of the ERP accounting system, it was necessary to communicate with end users and support the project in all phases of the life cycle, and provide training for end users and detailed testing of all system components before go life, and work together with the specific departments, set implementation strategies as a team mission and not just as new user software. It was necessary to emphasize accuracy and diligence when entering transactions or events and to be responsible and encourage open communication when entering data into the ERP system in terms of strategic decision-making.

A controlled survey was conducted to identify facts providing answers to research questions as to why companies need a better system like ERP:

- ERP should better integrate the key business processes.

- The system should facilitate the invoice approval process.

- The new system should reduce the need for IT support.

- Reduction of accounting costs.

- Facilitate consolidation and reporting in line with IFRS.

- Accurate and immediate audit data recording.

The development of industrial automation and globalization towards customers/companies/employees leads to the need for continuous innovation of processes, products/services. The implementation of such innovations is associated with additional costs beyond the scope of current operating expenditure invested in purchasing advanced automated control systems and information technologies with the application of innovative techniques, scientific procedures, research methods and professional training and learning to achieve the expected results. The ERP system implementation is a challenging milestone for most domestic and foreign companies in today's automation era with requirements for processing large volumes of data and transactions. If corporate goals and objectives were formulated other than in the interpretation of research methods this could lead to an incorrect definition of the very essence of the ERP accounting system and influence key results. Using a higher number of research methods could adversely affect the flow of information during the implementation of partial operations for a given project. It was necessary to consider innovations of the ERP system such as graphical outputs responding to real-time data changes, data visualization and their connection with arbitrary data sources, graphical redesign especially applicable to the values, mission and goals of the company. All the above values represent resources that are indispensable for a company. Research methods, data and staff training play an important role. They would be inefficient without planning and subsequent management of the output operations. Small and medium-sized enterprises should continuously pursue the improvement of business activities through innovations in all areas, including management, research and development, and production or sales. Predicted future expectations can be seen in innovative business and knowledge transfer partnerships, especially for SMEs, and integration toward customer 
satisfaction, creation of a competitive advantage, product / service cost reduction, market margin increase, compliance with corporate goals and objectives, but also the integrity and professionalism of company managers, owners and executives whose managerial decision-making is influenced by their resilience, well-being and mental hygiene.

\section{Acknowledgement}

The contribution is part of the project ERASMUS +, KA 205 Strategic Partnerships for Youth, Cooperation for innovation and the exchange of good practices. Project titled "Closing the Loop Along with the Youth".

\section{References}

1. AKHANOVA, M. A. et al., 2018, Methodology of estimating IT project efficiency. International Journal of Mechanical Engineering and Technology. 9(13), 803-809.

2. American University Washington, 2020. What is a Logframe? [online]. [2020-0515]. Available from: http://programs.online.american.edu.

3. ANDREEVA, L. Y. et al., 2019. Financial engineering of infrastructure projects: The concessional mechanism. International Journal of Economics and Business Administration. 7, 61-73.

4. ASTANAKULOV, 0. 2019. Real options as a financial instrument to evaluate a project with a high degree of uncertainty: The specifics of application. Economic Annals-XXI. 179, 105-114.

5. BERSHADSKY, A. et al., 2019. Integrated approach to the self-adaptive software development based on reflection and observation of the information environment. Proceedings - 2019 Actual Problems of Systems and Software Engineering, APSSE 2019, 8943813. 109-115.

6. BING, C., G. YANG, J. KANG, 2020. System implementation of a processing subcontracting business in SAP ERP non-standard subcontracting scenarios. Lecture Notes in Electrical Engineering. 640, 411-425.

7. BOČKOVÁ, K., G. GABRHELOVÁ, R. VANÍČKOVÁ, 2017. Risk management in Czech manufacturing company: Case study. International Journal of Applied Business and Economic Research. 15(19), 59-73.

8. COLAPINTO, C., R. JAYARAMAN, D. LA TORRE, 2020. Goal Programming Models for Managerial Strategic Decision Making. Studies in Systems, Decision and Control. 177, 487-507.

9. ERSKINE, M. A., M. KHOJAH, A. E. MCDANIEL, 2019. Location selection using heat maps: Relative advantage, task-technology fit, and decision-making performance. Computers in Human Behaviour. 101, 151-162.

10. FENG, X. et al., 2020. Mobile targeting in industrial marketing: Connecting with the right businesses. Industrial Marketing Management. 86, 65-76. 
11. GŁODZIŃSKI, E., 2019. Performance measurement of complex project: Framework and means supporting management of project-based organizations. International Journal of Information Systems and Project Management. 7(2), 21-34.

12. HUIKKU, J., T. HYVÖNEN, J. JÄRVINEN, 2017. The role of a predictive analytics project initiator in the integration of financial and operational forecasts. Baltic Journal of Management. 12(4), 427-446.

13. IZHAR, R. et al., 2018. Impact and challenges of requirements management in Enterprise Resource Planning (ERP) via ERP thesaurus. International Journal of Advanced Computer Science and Applications. 9(8), 247-258.

14. KITSIOS, F. et al., 2019. Information systems strategy in SMEs: critical factors of strategic planning in logistics. Kybernetes. 49(4), 1197-1212.

15. MARTÍNEZ-BLANCO, J., S. FORIN, M. FINKBEINER, 2020. Challenges of organizational LCA: lessons learned from road testing the guidance on organizational life cycle assessment. International Journal of Life Cycle Assessment. 25(2), 311-33.

16. MOUSAEI, M., T. J. GANDOMANI, 2018. A new project risk management model based on Scrum framework and Prince2 methodology. International Journal of Advanced Computer Science and Applications. 9(4), 442-449.

17. MY LE, H. T., P. T. HOANG TRAN, L. D. THUY TRAN, 2018. Factors influencing the effectiveness of the accounting information system: A case from Vietnamese firms. Journal for Global Business Advancement. 11(5), 587-609.

18. NÝVLT, V., 2018. Role of BIM process participants within managing knowledge in BIM data model. International Multidisciplinary Scientific Geo Conference Surveying Geology and Mining Ecology Management, SGEM. 18(5.3), 711-718.

19. PAN, G., S. TEOH, P. S. SEOW, 2014. Coordinating the processes of resource enrichment and capability deployment: Lessons from IT implementation at a medium-sized accounting firm. International Journal of Accounting and Information Management. 22(4), 357-374.

20. PEARSON, T., 2019. Goal Setting \& Team Management with OKR (Objectives and Key Results): Smart Project Management Skills for Effective Office Leadership, Business Focus, and Growth. How to manage people and employees. ISBN 978-1795006231.

21. PlODER, C., T. DILGER, R. BERNSTEINER, 2020. A framework to combine corporate budgeting with agile project management. CEUR Workshop Proceedings 2581. 19-23.

22. REISENWITZ, T. H., J. G. FOWLER, 2019. Information Sources and the Tourism Decision-making Process: An Examination of Generation X and Generation Y Consumers. Global Business Review. 20(6), 1372-1392.

23. SANKARAN, B., W. J. O'BRIEN, 2018. Impact of CIM Technologies and Agency Policies on Performance for Highway Infrastructure Projects. Journal of Construction Engineering and Management. 144(7), 04018052.

24. WU, P. et al., 2019. Work-in-Progress: Joint Network and Computing Resource Scheduling for Wireless Networked Control Systems. Proceedings - Real-Time Systems Symposium. 2018-December, 8603211, 181-184. 
25. WEI, Q. et al., 2020. Retailer vs. vendor managed inventory with considering stochastic learning effect. Journal of the Operational Research Society. 71(4), 628646.

\section{Contact address of the author:}

Radka Vaníčková, Ph.D., Department of Management, Faculty of Business Strategy, Institute of Technology and Business in České Budějovice, Czech Republic, e-mail vanickovaradka@gmail.com 


\section{Attachment}

\section{Tab. 1: Logical Frame Logframe}

\begin{tabular}{|c|c|c|c|c|}
\hline & $\begin{array}{l}\text { Project description, } \\
\text { content requirements }\end{array}$ & $\begin{array}{l}\text { Objectively verifiable } \\
\text { indicators }\end{array}$ & $\begin{array}{l}\text { Sources of } \\
\text { information for } \\
\text { measuring indicators }\end{array}$ & $\begin{array}{l}\text { External assumptions } \\
\text { and risks }\end{array}$ \\
\hline $\begin{array}{l}\text { The main } \\
\text { benefit of } \\
\text { the } \\
\text { project }\end{array}$ & $\begin{array}{l}\text { Reducing the costs of } \\
\text { accounting and auditing } \\
\text { administration in the } \\
\text { company. }\end{array}$ & $\begin{array}{l}\text { Thanks to the new } \\
\text { system, a lower number } \\
\text { of workers with a higher } \\
\text { volume of work will be } \\
\text { needed. }\end{array}$ & $\begin{array}{l}\text { The company's } \\
\text { budget and the annual } \\
\text { report of the finance } \\
\text { department within the } \\
\text { financial } \\
\text { documentation }\end{array}$ & $\begin{array}{l}\text { The cost of implementing } \\
\text { the new accounting system } \\
\text { will outweigh the } \\
\text { economies of scale. }\end{array}$ \\
\hline $\begin{array}{l}\text { Project } \\
\text { goal }\end{array}$ & $\begin{array}{l}\text { At the end of the fiscal } \\
\text { year, have a functioning } \\
\text { ERP accounting system } \\
\text { that is more efficient } \\
\text { than the previous } \\
\text { system and complies } \\
\text { with IFRS }{ }^{1} \text {. }\end{array}$ & $\begin{array}{l}\text { Number of posted } \\
\text { invoices/time, posting } \\
\text { time of } 1 \text { invoice, result } \\
\text { of external and internal } \\
\text { audit. }\end{array}$ & $\begin{array}{l}\text { Accounting system } \\
\text { report for the number } \\
\text { of operations } / 1 \\
\text { minute, Statistics of } \\
\text { the time required for } 1 \\
\text { automatically posted } \\
\text { invoice. Audit error } \\
\text { report. }\end{array}$ & $\begin{array}{l}\text { During the test period } \\
\text { before Go life, turnover of } \\
\text { key employees is expected } \\
\text { due to overwork, burnout } \\
\text { and insufficient motivation, } \\
\text { commitment and } \\
\text { dissatisfaction. }\end{array}$ \\
\hline $\begin{array}{l}\text { Project } \\
\text { outputs }\end{array}$ & $\begin{array}{l}\text { The time of each } \\
\text { accounting operation is } \\
\text { reduced. } \\
\text { Thanks to the } \\
\text { automation of the } \\
\text { system, there will be no } \\
\text { overtime for employees, } \\
\text { reducing the number of } \\
\text { permanent staff. } \\
\text { The individual steps in } \\
\text { the system will be } \\
\text { clearly documented for } \\
\text { audit and further } \\
\text { monitoring purposes. }\end{array}$ & $\begin{array}{l}\text { Posting time of one } \\
\text { invoice. } \\
\text { The number of } \\
\text { employees needed to } \\
\text { work in the previous } \\
\text { system and now. } \\
\text { Test audit team reports. }\end{array}$ & $\begin{array}{l}\text { IT reports reported by } \\
\text { the system, reports } \\
\text { from the existing ERP } \\
\text { system as a } \\
\text { comparison of } \\
\text { efficiency. } \\
\text { Employee timetables. }\end{array}$ & $\begin{array}{l}\text { The interface with the } \\
\text { existing database will work. } \\
\text { Employees will not feel } \\
\text { threatened by the full } \\
\text { automation of the system } \\
\text { and will cooperate in testing } \\
\text { it (automation will reduce } \\
\text { the number of jobs). }\end{array}$ \\
\hline $\begin{array}{l}\text { Project } \\
\text { activities }\end{array}$ & $\begin{array}{l}\text { Testing the new system } \\
\text { on a daily basis. } \\
\text { Filling in test protocols. } \\
\text { Collaborate with IT to } \\
\text { improve system } \\
\text { performance and } \\
\text { eliminate deficiencies. } \\
\text { Preparation of an error } \\
\text { report. }\end{array}$ & $\begin{array}{l}\text { Installation of a test } \\
\text { version of the new ERP } \\
\text { accounting system into } \\
\text { the PC of permanent } \\
\text { staff. } \\
\text { Training and manual for } \\
\text { the new accounting } \\
\text { system. } \\
\text { Pre-prepared protocols } \\
\text { for completion. } \\
\text { Preparation of written } \\
\text { statements by the } \\
\text { manager. }\end{array}$ & $\begin{array}{l}\text { Comparison tables of } \\
\text { time intensity of } \\
\text { individual accounting } \\
\text { operations in the old } \\
\text { and new system. }\end{array}$ & $\begin{array}{l}\text { The test version of the } \\
\text { system will not work at the } \\
\text { same speed as in real time, } \\
\text { i.e. it is not possible to } \\
\text { objectively compare the } \\
\text { obtained results. } \\
\text { Removal of the weaknesses } \\
\text { will be formal. }\end{array}$ \\
\hline
\end{tabular}

Source: Author.

${ }^{1}$ IFRS (International Financial Reporting Standards). 